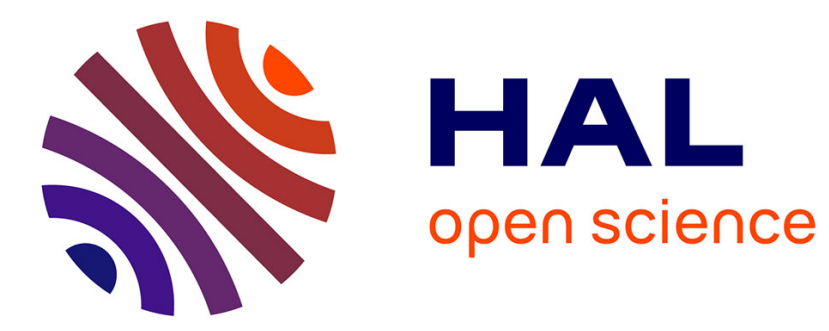

\title{
Conditions for the Simultaneous Stabilizability of a Segment of Systems
}

\author{
Christophe Fonte
}

\section{To cite this version:}

Christophe Fonte. Conditions for the Simultaneous Stabilizability of a Segment of Systems. American Control Conference, ACC 2008, Jun 2008, Seattle, United States. pp.3654-3659, 10.1109/ACC.2008.4587061 . hal-00347494

\section{HAL Id: hal-00347494 \\ https://hal.science/hal-00347494}

Submitted on 16 Dec 2008

HAL is a multi-disciplinary open access archive for the deposit and dissemination of scientific research documents, whether they are published or not. The documents may come from teaching and research institutions in France or abroad, or from public or private research centers.
L'archive ouverte pluridisciplinaire HAL, est destinée au dépôt et à la diffusion de documents scientifiques de niveau recherche, publiés ou non, émanant des établissements d'enseignement et de recherche français ou étrangers, des laboratoires publics ou privés. 


\title{
Conditions for the Simultaneous Stabilizability of a Segment of Systems
}

\author{
Christophe FONTE
}

\begin{abstract}
This paper examines conditions for the simultaneous stabilizability of a segment of linear systems. It is proved that conditions on the negative real axis of the Nyquist plot to ensure the Hurwitzness of the corresponding Diophantine equation are equivalent to some criteria of positive semidefinite matrix and of sums of squares of polynomials. Finally, these results yield to a tractable method to test the simultaneous stabilizability of uncertain segments of systems when it may be given a simultaneous compensator for the two endpoints of this segment.
\end{abstract}

\section{INTRODUCTION}

This paper regards the questions of the simultaneous stabilizability of a family of single input single output systems $G_{\lambda}(s)$ which are assumed to be linear, time invariant represented by a segment of uncertain systems as hereafter

$$
G_{\lambda}(s)=\frac{N_{\lambda}(s)}{D_{\lambda}(s)}=\frac{(1-\lambda) N_{1}(s)+\lambda N_{0}(s)}{(1-\lambda) D_{1}(s)+\lambda D_{0}(s)}, \lambda \in[0,1]
$$

with $N_{\lambda}(s)$ and $D_{\lambda}(s)$ defined as two line segments of real polynomials of constant degree and $N_{1}(s), N_{0}(s), D_{1}(s)$, $D_{0}(s)$ are real polynomials . This family of systems (1) may be viewed as a continuum of transfer functions described by the two distinct transfer functions $G_{0}(s)$ and $G_{1}(s)$ given by $\lambda=1$ and $\lambda=0$ respectively.

The objective of this paper is to present some solutions to the basic control problem: "For a whole segment of systems given by (1), is there one single controller $C(s)$ ?". In this paper, simultaneous stabilizability existence conditions for a segment of systems such that (1) will be given.

One can notice that this family of uncertain systems has attracted the attention of many researchers worried by the problem of strong stabilization, see [6], [8]. These authors have stated existence conditions of stable regulators being able to stabilize each members belonging to this family (1). That does not imply existence conditions of a single controller that stabilizes the whole set of systems. This problem is more complex. The question of the simultaneous stabilization of a segment of systems given by (1) was initially tackled by [9], [10] and [1] but no tractable and complete conditions to check the simultaneous stabilizability of such systems have been given. To study in a satisfactory way this question, it is useful to consider the works in the area of the simultaneous control as well as those formulated in the topic of the polynomial control of uncertain systems, see [2], [12], [5], [7], [11].

Nancy-Université, CNRS,

Centre de Recherche en Automatique de Nancy (CRAN), UMR 7039,

Christophe.Fontedcran.uhp-nancy. fr
In this paper, necessary and sufficient conditions will be given for simultaneously stabilizing the segment of systems (1) when there exist a simultaneous compensator $C(s)$ for the two endpoints of this segment. These conditions depend only of $G_{0}(s), G_{1}(s)$ and $C(s)$.

\section{PROBLEM FORMULATION}

First of all, let us give some notations.

1) $\mathbb{R}^{+}{ }_{-\{0\}}$ denotes the set of strictly positive reals belonging to the interval $] 0, \infty]$.

2) $\mathbb{C}_{-}$denotes the open left half complex plane $\mathbb{C}$.

The problem of the simultaneous stabilization of a family of systems $G_{\lambda}(s)$ as described in (1) may be translated into the following way: "Does there exist a compensator $C(s)$ stabilizing all the systems belonging to the family $G_{\lambda}(s)$ whatever $\lambda \in[0,1]$ ?" or "do there exist two real polynomials $X(s)$ and $Y(s),(Y(s) \neq 0)$ such that the closed-loop segment of systems $G_{\lambda}(s)\left(1+C(s) G_{\lambda}(s)\right)^{-1}$ has all its poles in $\mathbb{C}_{-}, \forall \lambda \in[0,1]$ ?" What means examining the existence conditions of two polynomials $X(s)$ and $Y(s)$ solutions of the following Diophantine equation

$$
\lambda \in[0,1], \quad A_{\lambda}(s)=X(s) N_{\lambda}(s)+Y(s) D_{\lambda}(s)
$$

where $A_{\lambda}(s)$ is an Hurwitz polynomial segment of constant degree for all $\lambda \in[0,1]$, i.e. all the polynomials belonging to this segment (2) are Hurwitz. If $A_{\lambda}(s)$ is not of same degree for all $\lambda \in[0,1]$ then this loss of degree also implies loss of bounded-input bounded-output stability. The relationship (2) is rewritten like the following one

$$
\begin{aligned}
\lambda \in[0,1], A_{\lambda}(s)= & (1-\lambda)\left(X(s) N_{1}(s)+Y(s) D_{1}(s)\right)+ \\
& \lambda\left(X(s) N_{0}(s)+Y(s) D_{0}(s)\right)
\end{aligned}
$$

To examine the existence conditions of the solutions $X(s)$ and $Y(s)$ of (3), it is equivalent to check that there exists a compensator $C(s)$ for the system (1) such that the roots of the polynomial $A_{\lambda}(s)$ are all in $\mathbb{C}_{-}$for any $\lambda \in[0,1]$. Hence, the problem of the Hurwitzness of the uncertain polynomial $A_{\lambda}(s)$ requires the existence of two Hurwitz polynomials $A_{0}(s)$ and $A_{1}(s)$ given by (5) that must verify the equality (4) hereafter

$$
\lambda \in[0,1], \quad A_{\lambda}(s)=(1-\lambda) A_{1}(s)+\lambda A_{0}(s)
$$

where

$$
\left\{\begin{array}{l}
A_{0}(s)=X(s) N_{0}(s)+Y(s) D_{0}(s) \\
A_{1}(s)=X(s) N_{1}(s)+Y(s) D_{1}(s)
\end{array}\right.
$$

The two Hurwitz polynomials $A_{0}(s)$ and $A_{1}(s)$ are assumed to be of same degree and same signs (i.e. $\left.A_{0}(0) A_{1}(0)>0\right)$, see [4], [6]. 
In this presentation, we assume that there exist a simultaneous compensator $C(s)$ for the two systems $G_{0}(s)$ and $G_{1}(s)$ verifying the relations (5). We shall study the conditions for that this compensator stabilizes also simultaneously the whole segment of systems (1). Algebraic necessary and sufficient conditions will be given so that the Diophantine equation (2) is Hurwitz when the two endpoints of this polynomial segment $A_{0}(s)$ and $A_{1}(s)$ are Hurwitz and of same sign and of same degree.

\section{HURWITZNESS OF THE SEGMENT $A_{\lambda}(s)$}

Before developing the main results, let us recall the following theorem.

Theorem 1: [4], Let us consider the polynomial segment $A_{\lambda}(s)$ given by (3) with the two Hurwitz polynomials $A_{0}(s)$ and $A_{1}(s)$ of same degree and of same sign. Then, the segment $A_{\lambda}(s)$ is Hurwitz and of constant degree if and only if the rational function $\frac{A_{1}(s)}{A_{0}(s)}$ does not cut the negative real axis of the Nyquist plot.

This condition is a direct consequence of the "Boundary Crossing Theorem", see [4] which reduces here the Hurwitzness of $A_{\lambda}(s)$ to the study on the complex plane of the frequency domain image of this segment. For explaining this result, it is necessary to recall that by hypothesis the segment $A_{\lambda}(s)$ is assumed to be of constant degree. In these conditions, the parametric continuity of the space of polynomial family when $\lambda$ moves in a continuous way implies also the continuity of the space of the family of zeros. Then the Hurwitzness of the polynomial $A_{\lambda}(s)$ is guaranteed, see [3], if and only if firstly one polynomial of this family is stable and secondly for any $\lambda \in[0,1]$, the polynomial family $A_{\lambda}(s)$ does not have zeros on the imaginary axis.

$$
\forall \lambda \in[0,1] \text { and } \forall w \in \mathbb{R}_{-\{0\}}^{+}, A_{\lambda}(j w) \neq 0,
$$

or

$$
\forall \lambda \in[0,1], \quad \forall w \in \mathbb{R}^{+}{ }_{-\{0\}}, \quad \frac{A_{1}(j w)}{A_{0}(j w)} \neq-\frac{\lambda}{(1-\lambda)}
$$

Consequently if the condition (7) is checked, the rational function $\frac{A_{1}(s)}{A_{0}(s)}$ cannot cut the negative real axis of the Nyquist plot and all the zeros of the polynomial family $A_{\lambda}(s)$ are in $\mathbb{C}_{-}$. After these recalls, let us rewrite (7) in another manner. For that, let us consider the following relationships

$$
\begin{aligned}
& A_{0}(s)=A_{0}^{\text {even }}(s)+A_{0}^{\text {odd }}(s) \\
& A_{1}(s)=A_{1}^{\text {even }}(s)+A_{1}^{\text {odd }}(s)
\end{aligned}
$$

such that

$$
\left\{\begin{array}{l}
A_{0}^{\text {even }}(s)=a_{0,0}+a_{0,2} s^{2}+\ldots+a_{0,2 i} s^{2 i} \\
A_{0}^{\text {odd }}(s)=a_{0,1} s+a_{0,3} s^{3}+a_{0,5} s^{5}+\ldots .+a_{0,2 i+1} s^{2 i+1} \\
A_{1}^{\text {even }}(s)=a_{1,0}+a_{1,2} s^{2}+\ldots+a_{1,2 i} s^{2 i} \\
A_{1}^{\text {odd }}(s)=a_{1,1} s+a_{1,3} s^{3}+a_{1,5} s^{5}+\ldots+a_{1,2 i+1} s^{2 i+1}
\end{array}\right.
$$

Consider $s=j w$. Then, we have

$$
\begin{aligned}
& A_{0}(j w)=A_{0}^{e}(j w)+j w A_{0}^{o}(j w) \\
& A_{1}(j w)=A_{1}^{e}(j w)+j w A_{1}^{o}(j w)
\end{aligned}
$$

with

$$
\left\{\begin{array}{l}
A_{0}^{\text {even }}(j w)=A_{0}^{e}(j w) \\
A_{0}^{\text {odd }}(j w)=j w A_{0}^{o}(j w) \\
A_{1}^{\text {even }}(j w)=A_{1}^{e}(j w) \\
A_{1}^{\text {odd }}(j w)=j w A_{1}^{o}(j w)
\end{array}\right.
$$

Theorem 2: Let $A_{0}(s)$ and $A_{1}(s)$ be two Hurwitz polynomials of same degree and of same sign and let us assume that there are strictly positive real zeros $w_{i}$ such as

$$
A_{0}^{e}\left(j w_{i}\right) A_{1}^{o}\left(j w_{i}\right)-A_{0}^{o}\left(j w_{i}\right) A_{1}^{e}\left(j w_{i}\right)=0
$$

Then, the polynomial segment $A_{\lambda}(s)$ defined by (3) is Hurwitz if and only if the scalars $w_{i}$ verify the constraint (12a) or the constraint (12b).

$$
\begin{aligned}
& A_{0}^{e}\left(j w_{i}\right) A_{1}^{e}\left(j w_{i}\right)>0 \\
& A_{0}^{o}\left(j w_{i}\right) A_{1}^{o}\left(j w_{i}\right)>0
\end{aligned}
$$

In the case where there exists none strictly positive real zero $w_{i}$ such that (11) holds, the segment $A_{\lambda}(s)$ is Hurwitz.

Proof: Let us assume Theorem 1 checked. Thus, we can rewrite the relation (7) by considering (9) as it follows $\forall \lambda \in[0,1]$ and $\forall w \in \mathbb{R}^{+}{ }_{-\{0\}}$,

$$
\frac{A_{1}^{e}(j w)+j w A_{1}^{o}(j w)}{A_{0}^{e}(j w)+j w A_{0}^{o}(j w)} \neq-\frac{\lambda}{(1-\lambda)}
$$

That is equivalent to say that for all $\lambda \in[0,1]$ and for all $w \in \mathbb{R}^{+}{ }_{-}\{0\}$, we have

$$
\frac{\left(A_{1}^{e}(j w)+j w A_{1}^{o}(j w)\right)\left(A_{0}^{e}(j w)-j w A_{0}^{o}(j w)\right)}{\left(A_{0}^{e}(j w)+j w A_{0}^{o}(j w)\right)\left(A_{0}^{e}(j w)-j w A_{0}^{o}(j w)\right)} \neq-\frac{\lambda}{(1-\lambda)}
$$

If we denote by $\widehat{\chi}(j w)$ and $\widehat{\delta}(j w)$ the following expressions

$$
\left\{\begin{array}{l}
\widehat{\chi}(j w)=\frac{A_{1}^{e}(j w) A_{0}^{e}(j w)+w^{2} A_{1}^{o}(j w) A_{0}^{o}(j w)}{A_{0}^{e}(j w) A_{0}^{e}(j w)+w^{2} A_{0}^{o}(j w) A_{0}^{o}(j w)} \\
\widehat{\delta}(j w)=\frac{A_{0}^{e}(j w) A_{1}^{o}(j w)-A_{0}^{o}(j w) A_{1}^{e}(j w)}{A_{0}^{e}(j w) A_{0}^{e}(j w)+w^{2} A_{0}^{o}(j w) A_{0}^{o}(j w)}
\end{array}\right.
$$

Hence, we can rewrite the relationship (13) for all $\lambda \in$ $[0,1]$ and for all $w \in \mathbb{R}^{+}{ }_{-\{0\}}$ as

$$
\widehat{\chi}(j w)+j w \widehat{\delta}(j w) \neq-\frac{\lambda}{(1-\lambda)}
$$

The existence conditions given by the inequality (15) may be decomposed as the two following cases

1) If for all $w \in \mathbb{R}^{+}{ }_{-\{0\}}, \widehat{\delta}(j w) \neq 0$, then (15) holds.

2) If there exists $w \in \mathbb{R}^{+}{ }_{-\{0\}}$ such that $\widehat{\delta}(j w)=0$ and $\widehat{\chi}(j w)>0$, then (15) holds.

The first case is obvious. Let us study the second case. For that, we can observe that to check the inequality (15) is equivalent to find the positive real zeros $w_{i}$ of $\widehat{\delta}(j w)$ and to check if these zeros yield to $\widehat{\chi}\left(j w_{i}\right)>0$. Equivalently, the real part of the unit $\frac{A_{1}(j w)}{A_{0}(j w)}$ in the Nyquist plot must be strictly positive when the imaginary part of this unit is null. Let us denote by $\mathfrak{W}$, the set of strictly positive real zeros $w_{i}$ of $\widehat{\delta}(j w)$. The equality $\widehat{\delta}\left(j w_{i}\right)=0$ may be written like one of the two following relations (16) or (17).

1) If there is $w_{i} \in \mathfrak{W}$ such that $A_{1}^{e}\left(j w_{i}\right) \neq 0$ and $A_{0}^{e}\left(j w_{i}\right) \neq 0$, then we have

$$
\frac{A_{1}^{o}\left(j w_{i}\right)}{A_{1}^{e}\left(j w_{i}\right)}=\frac{A_{0}^{o}\left(j w_{i}\right)}{A_{0}^{e}\left(j w_{i}\right)}
$$


2) If there is $w_{i} \in \mathfrak{W}$ such that $A_{1}^{o}\left(j w_{i}\right) \neq 0$ and $A_{0}^{o}\left(j w_{i}\right) \neq 0$, then we have

$$
\frac{A_{1}^{e}\left(j w_{i}\right)}{A_{1}^{o}\left(j w_{i}\right)}=\frac{A_{0}^{e}\left(j w_{i}\right)}{A_{0}^{o}\left(j w_{i}\right)}
$$

Note that the cases $A_{0}^{e}\left(j w_{i}\right)=0$ and $A_{0}^{o}\left(j w_{i}\right)=0$ or $A_{1}^{e}\left(j w_{i}\right)=0$ and $A_{1}^{o}\left(j w_{i}\right)=0$ are not possible thus if $A_{0}^{e}\left(j w_{i}\right)=0$ and $A_{0}^{o}\left(j w_{i}\right)=0$ then $A_{0}^{e}\left(j w_{i}\right)$ and $A_{0}^{o}\left(j w_{i}\right)$ have the same root. In the same way, if $A_{1}^{e}\left(j w_{i}\right)=0$ and $A_{1}^{o}\left(j w_{i}\right)=0$ then $A_{1}^{e}\left(j w_{i}\right)$ and $A_{1}^{o}\left(j w_{i}\right)$ have the same root. In these conditions, the polynomials $A_{0}(s)$ and $A_{1}(s)$ do not satisfy the Hermite-Biehler Theorem, see [14]. Consequently these polynomials are not Hurwitz. That is in contradiction with the starting assumption.

For examining the two cases (16) and (17) in regard to the condition $\widehat{\chi}\left(j w_{i}\right)>0$, let us translate the condition $\hat{\chi}\left(j w_{i}\right)>0$ into the two possible factorizations as listed hereafter.

1) Let us consider the case where there is $w_{i} \in \mathfrak{W}$ such that $A_{0}^{e}\left(j w_{i}\right) \neq 0$ and $A_{1}^{e}\left(j w_{i}\right) \neq 0$. Then $\widehat{\chi}\left(j w_{i}\right)$ will be strictly positive if we have

$$
\begin{aligned}
\widehat{\chi}\left(j w_{i}\right)= & A_{0}^{e}\left(j w_{i}\right) A_{1}^{e}\left(j w_{i}\right)\left(1+w_{i}^{2} \frac{A_{0}^{o}\left(j w_{i}\right) A_{0}^{o}\left(j w_{i}\right)}{A_{0}^{e}\left(j w_{i}\right) A_{0}^{e}\left(j w_{i}\right)}\right) \times \\
& \left(\frac{1}{A_{0}^{e}\left(j w_{i}\right) A_{0}^{e}\left(j w_{i}\right)+w_{i}^{2} A_{0}^{o}\left(j w_{i}\right) A_{0}^{o}\left(j w_{i}\right)}\right)>0
\end{aligned}
$$

As the following inequalities are always satisfied for any $w_{i} \in \mathfrak{W}$,

$$
\begin{aligned}
\left(1+w_{i}^{2} \frac{A_{0}^{o}\left(j w_{i}\right) A_{0}^{o}\left(j w_{i}\right)}{A_{0}^{e}\left(j w_{i}\right) A_{0}^{e}\left(j w_{i}\right)}\right) & >0 \\
\left(\frac{1}{A_{0}^{e}\left(j w_{i}\right) A_{0}^{e}\left(j w_{i}\right)+w_{i}^{2} A_{0}^{o}\left(j w_{i}\right) A_{0}^{o}\left(j w_{i}\right)}\right) & >0
\end{aligned}
$$

the following relationship (18) must be only checked

$$
A_{0}^{e}\left(j w_{i}\right) A_{1}^{e}\left(j w_{i}\right)>0
$$

2) Now, we consider the case where there is $w_{i} \in \mathfrak{W}$ such that $A_{0}^{o}\left(j w_{i}\right) \neq 0$ and $A_{1}^{o}\left(j w_{i}\right) \neq 0$. The relationship $\widehat{\chi}\left(j w_{i}\right)>0$ can be rewritten in the equivalent form

$$
\begin{array}{r}
\widehat{\chi}\left(j w_{i}\right)=A_{0}^{o}\left(j w_{i}\right) A_{1}^{o}\left(j w_{i}\right)\left(w_{i}^{2}+\frac{A_{0}^{e}\left(j w_{i}\right) A_{0}^{e}\left(j w_{i}\right)}{A_{0}^{o}\left(j w_{i}\right) A_{0}^{o}\left(j w_{i}\right)}\right) \\
\left(\frac{1}{A_{0}^{e}\left(j w_{i}\right) A_{0}^{e}\left(j w_{i}\right)+w_{i}^{2} A_{0}^{o}\left(j w_{i}\right) A_{0}^{o}\left(j w_{i}\right)}\right)>0
\end{array}
$$

As the following inequalities are satisfied for any $w_{i} \in \mathfrak{W}$,

$$
\begin{aligned}
\left(w_{i}^{2}+\frac{A_{0}^{e}\left(j w_{i}\right) A_{0}^{e}\left(j w_{i}\right)}{A_{0}^{o}\left(j w_{i}\right) A_{0}^{o}\left(j w_{i}\right)}\right) & >0 \\
\left(\frac{1}{A_{0}^{e}\left(j w_{i}\right) A_{0}^{e}\left(j w_{i}\right)+w_{i}^{2} A_{0}^{o}\left(j w_{i}\right) A_{0}^{o}\left(j w_{i}\right)}\right) & >0
\end{aligned}
$$

the following relationship must be only checked

$$
A_{0}^{o}\left(j w_{i}\right) A_{1}^{o}\left(j w_{i}\right)>0
$$

To conclude this proof, let us remark that if there is $w_{i} \in$ $\mathfrak{W}$ such that $A_{0}^{e}\left(j w_{i}\right) \neq 0, A_{1}^{e}\left(j w_{i}\right) \neq 0, A_{0}^{o}\left(j w_{i}\right) \neq 0$ and $A_{1}^{o}\left(j w_{i}\right) \neq 0$, it suffices to consider one of the two relations (16) or (17), i.e. to test that the no null real zero $w_{i}$ verifies one of the two inequalities (18) or (19).

\section{A SEMI-DEFINITE POSITIVE TEST}

In the previous section, we have showed that to ensure the stability of the segment $A_{\lambda}(s)$, it is necessary and sufficient to check that the two Hurwitz polynomials $A_{0}(s)$ and $A_{1}(s)$ verify Theorem 2 . In this part, an equivalent formulation based on matrix decompositions of (12a) and (12b) is presented. Then, a test to check the semi-positivity of these polynomial forms will be introduced .

Let us consider the two polynomials $A_{0}(s)$ and $A_{1}(s)$ as seen in (5) and let us compute the polynomials $X(j w)$, $Y(j w), N_{0}(j w), D_{0}(j w), N_{1}(j w), D_{1}(j w)$ similarly than (8) and (9) with the odd and even parts given by $X^{e}(j w)$, $X^{o}(j w), Y^{e}(j w), Y^{o}(j w), N_{0}^{e}(j w), N_{0}^{o}(j w), D_{0}^{e}(j w)$, $D_{0}^{o}(j w), N_{1}^{e}(j w), N_{1}^{o}(j w), D_{1}^{e}(j w), D_{1}^{o}(j w)$. Then in accordance with (10), the relationships (9) are rewritten as

$$
\left\{\begin{array}{l}
A_{0}(j w)=A_{0}^{e}(j w)+j w A_{0}^{o}(j w)= \\
\left(X^{e}(j w)+j w X^{o}(j w)\right)\left(N_{0}^{e}(j w)+j w N_{0}^{o}(j w)\right)+ \\
\left(Y^{e}(j w)+j w Y^{o}(j w)\right)\left(D_{0}^{e}(j w)+j w D_{0}^{o}(j w)\right) \\
A_{1}(j w)=A_{1}^{e}(j w)+j w A_{1}^{o}(j w)= \\
\left(X^{e}(j w)+j w X^{o}(j w)\right)\left(N_{1}^{e}(j w)+j w N_{1}^{o}(j w)\right)+ \\
\left(Y^{e}(j w)+j w Y^{o}(j w)\right)\left(D_{1}^{e}(j w)+j w D_{1}^{o}(j w)\right)
\end{array}\right.
$$

with

$$
\left\{\begin{aligned}
A_{0}^{e}(j w)= & N_{0}^{e}(j w) X^{e}(j w)-w^{2} N_{0}^{o}(j w) X^{o}(j w) \\
& +D_{0}^{e}(j w) Y^{e}(j w)-w^{2} D_{0}^{o}(j w) Y^{o}(j w) \\
A_{0}^{o}(j w)= & N_{0}^{e}(j w) X^{o}(j w)+N_{0}^{o}(j w) X^{e}(j w) \\
& +D_{0}^{e}(j w) Y^{o}(j w)+D_{0}^{o}(j w) Y^{e}(j w) \\
A_{1}^{e}(j w)= & N_{1}^{e}(j w) X^{e}(j w)-w^{2} N_{1}^{o}(j w) X^{o}(j w) \\
& +D_{1}^{e}(j w) Y^{e}(j w)-w^{2} D_{1}^{o}(j w) Y^{o}(j w) \\
A_{1}^{o}(j w)= & N_{1}^{e}(j w) X^{o}(j w)+N_{1}^{o}(j w) X^{e}(j w) \\
& +D_{1}^{e}(j w) Y^{o}(j w)+D_{1}^{o}(j w) Y^{e}(j w)
\end{aligned}\right.
$$

Let us examine the positive real zeros $w_{i}$ of $\widehat{\delta}(j w)$ by using relations (20), in order to formulate the signs of the expressions $A_{0}^{e}\left(j w_{i}\right) A_{1}^{e}\left(j w_{i}\right)$ and $A_{0}^{o}\left(j w_{i}\right) A_{1}^{o}\left(j w_{i}\right)$.

\section{A. Study of the positive real zeros of $\widehat{\delta}(j w)$}

Let us assume that there exists a simultaneous controller $C(s)$ for the two plants $G_{0}(s)$ and $G_{1}(s)$ such as the two Hurwitz polynomials $A_{0}(s)$ and $A_{1}(s)$ given by (5) have the same degree and verify $A_{0}(0) A_{1}(0)>0$. To find the positive real zeros of $\widehat{\delta}(j w)$, we write

$$
\begin{gathered}
\exists w \in \mathbb{R}^{+}{ }_{-\{0\}} \quad \text { such as } \\
A_{0}^{e}(j w) A_{1}^{o}(j w)-A_{0}^{o}(j w) A_{1}^{e}(j w)=0
\end{gathered}
$$

By considering (20), relation (21) may be decomposed into two parts: $A_{0}^{e}(j w) A_{1}^{o}(j w)$ and $A_{0}^{o}(j w) A_{1}^{e}(j w)$.

$$
A_{0}^{e}(j w) A_{1}^{o}(j w)=
$$

$N_{0}^{e}(j w) X^{e}(j w) N_{1}^{e}(j w) X^{o}(j w)+N_{0}^{e}(j w) X^{e}(j w) N_{1}^{o}(j w) X^{e}(j w)$ $+N_{0}^{e}(j w) X^{e}(j w) D_{1}^{e}(j w) Y^{o}(j w)+N_{0}^{e}(j w) X^{e}(j w) D_{1}^{o}(j w) Y^{e}(j w)$

$-w^{2}\left(N_{0}^{o}(j w) X^{o}(j w) N_{1}^{e}(j w) X^{o}(j w)+N_{0}^{o}(j w) X^{o}(j w) N_{1}^{o}(j w) X^{e}(j w)\right.$ $\left.+N_{0}^{o}(j w) X^{o}(j w) D_{1}^{e}(j w) Y^{o}(j w)+N_{0}^{o}(j w) X^{o}(j w) D_{1}^{o}(j w) Y^{e}(j w)\right)$ $+D_{0}^{e}(j w) Y^{o}(j w) N_{1}^{e}(j w) X^{e}(j w)+D_{0}^{e}(j w) Y^{o}(j w) N_{1}^{o}(j w) X^{e}(j w)$ $+D_{0}^{e}(j w) Y^{e}(j w) D_{1}^{e}(j w) Y^{o}(j w)+D_{0}^{e}(j w) Y^{e}(j w) D_{1}^{o}(j w) Y^{e}(j w)$ $-w^{2}\left(D_{0}^{o}(j w) Y^{o}(j w) N_{1}^{e}(j w) X^{o}(j w)+D_{0}^{o}(j w) Y^{o}(j w) N_{1}^{o}(j w) X^{e}(j w)\right.$ $\left.+D_{0}^{o}(j w) Y^{e}(j w) D_{1}^{e}(j w) Y^{o}(j w)+D_{0}^{o}(j w) Y^{o}(j w) D_{1}^{o}(j w) Y^{e}(j w)\right)$ 
$A_{0}^{o}(j w) A_{1}^{e}(j w)=$

$N_{0}^{e}(j w) X^{o}(j w) N_{1}^{e}(j w) X^{e}(j w)-w^{2} N_{0}^{e}(j w) X^{o}(j w) N_{1}^{o}(j w) X^{o}(j w)$ $+N_{0}^{e}(j w) X^{o}(j w) D_{1}^{e}(j w) Y^{e}(j w)-w^{2} N_{0}^{e}(j w) X^{o}(j w) D_{1}^{o}(j w) Y^{o}(j w)$ $+N_{0}^{o}(j w) X^{e}(j w) N_{1}^{e}(j w) X^{e}(j w)-w^{2} N_{0}^{o}(j w) X^{e}(j w) N_{1}^{o}(j w) X^{o}(j w)$ $+N_{0}^{o}(j w) X^{e}(j w) D_{1}^{e}(j w) Y^{e}(j w)-w^{2} N_{0}^{o}(j w) X^{e}(j w) D_{1}^{o}(j w) Y^{o}(j w)$ $+D_{0}^{e}(j w) Y^{o}(j w) N_{1}^{e}(j w) X^{e}(j w)-w^{2} D_{0}^{e}(j w) Y^{o}(j w) N_{1}^{o}(j w) X^{o}(j w)$ $+D_{0}^{e}(j w) Y^{o}(j w) D_{1}^{e}(j w) Y^{e}(j w)-w^{2} D_{0}^{e}(j w) Y^{o}(j w) D_{1}^{o}(j w) Y^{o}(j w)$ $+D_{0}^{o}(j w) Y^{e}(j w) N_{1}^{e}(j w) X^{e}(j w)-w^{2} D_{0}^{o}(j w) Y^{e}(j w) N_{1}^{o}(j w) X^{o}(j w)$ $+D_{0}^{o}(j w) Y^{e}(j w) D_{1}^{e}(j w) Y^{e}(j w)-w^{2} D_{0}^{o}(j w) Y^{e}(j w) D_{1}^{o}(j w) Y^{o}(j w)$

Now, the relation (21) may be expressed as follows

$A_{0}^{e}(j w) A_{1}^{o}(j w)-A_{0}^{o}(j w) A_{1}^{e}(j w)=\varphi^{T}(j w) \operatorname{Mat}_{I}(j w) \psi(j w)$

with

$$
\begin{gathered}
\varphi^{T}(j w)=\left[X^{o}(j w) X^{e}(j w) Y^{o}(j w) Y^{e}(j w)\right] \\
\psi^{T}(j w)=\left[X^{e}(j w)-w^{2} X^{o}(j w) Y^{e}(j w)-w^{2} Y^{o}(j w)(23)\right.
\end{gathered}
$$

and

$\operatorname{Mat}_{I}(j w)=$

$$
\left(\begin{array}{cccc}
0 & m_{1,2}(j w) & m_{1,3}(j w) & m_{1,4}(j w) \\
-m_{1,2}(j w) & 0 & m_{2,3}(j w) & m_{2,4}(j w) \\
-m_{1,3}(j w) & -m_{2,3}(j w) & 0 & m_{3,4}(j w) \\
-m_{1,4}(j w) & -m_{2,4}(j w) & -m_{3,4}(j w) & 0
\end{array}\right)
$$

such that

$$
\begin{aligned}
& m_{1,2}(j w)=N_{0}^{o}(j w) N_{1}^{e}(j w)-N_{0}^{e}(j w) N_{1}^{o}(j w) \\
& m_{1,3}(j w)=D_{0}^{e}(j w) N_{1}^{e}(j w)-N_{0}^{e}(j w) D_{1}^{e}(j w) \\
& m_{1,4}(j w)=D_{0}^{o}(j w) N_{1}^{e}(j w)-N_{0}^{e}(j w) D_{1}^{o}(j w) \\
& m_{2,3}(j w)=D_{0}^{e}(j w) N_{1}^{o}(j w)-N_{0}^{o}(j w) D_{1}^{e}(j w) \\
& m_{2,4}(j w)=D_{0}^{o}(j w) N_{1}^{o}(j w)-N_{0}^{o}(j w) D_{1}^{o}(j w) \\
& m_{3,4}(j w)=D_{0}^{o}(j w) D_{1}^{e}(j w)-D_{0}^{e}(j w) D_{1}^{o}(j w)
\end{aligned}
$$

We remark that $\operatorname{Mat}_{I}(j w)$ is an antisymmetric matrix which depends only on the parameters of $G_{0}(j w)$ and $G_{1}(j w)$ and which is independent of the polynomials $X(j w)$ and $Y(j w)$. Hence, for any $X(j w)$ and $Y(j w)$ the relationship (21) is equivalent to

$$
\begin{array}{r}
\exists w \in \mathbb{R}^{+}{ }_{-\{0\}}, \forall \varphi(j w) \neq 0, \forall \psi(j w) \neq 0 \\
\text { such that } \varphi^{T}(j w) \operatorname{Mat}_{I}(j w) \psi(j w)=0
\end{array}
$$

$$
\text { or } \quad \exists w \in \mathbb{R}^{+}{ }_{-\{0\}} \text { such that } \operatorname{Mat}_{I}(j w)=0
$$

To check relation (26), we must search the common zeros of each term of the matrix $\operatorname{Mat}_{I}(j w)$, i.e. studying the common roots of all polynomials $m_{i, j}(j w)$. Let us denote by $w_{i}$ the common roots of $(25 \mathrm{a}),(25 \mathrm{~b}),(25 \mathrm{c}),(25 \mathrm{~d}),(25 \mathrm{e})$ and (25f). Then, condition (26), i.e. $\operatorname{Mat}_{I}\left(j w_{i}\right)=0$ yields to

$$
\begin{aligned}
& m_{1,2}\left(j w_{i}\right)=N_{0}^{o}\left(j w_{i}\right) N_{1}^{e}\left(j w_{i}\right)-N_{0}^{e}\left(j w_{i}\right) N_{1}^{o}\left(j w_{i}\right)=0 \\
& m_{1,3}\left(j w_{i}\right)=D_{0}^{e}\left(j w_{i}\right) N_{1}^{e}\left(j w_{i}\right)-N_{0}^{e}\left(j w_{i}\right) D_{1}^{e}\left(j w_{i}\right)=0 \\
& m_{1,4}\left(j w_{i}\right)=D_{0}^{o}\left(j w_{i}\right) N_{1}^{e}\left(j w_{i}\right)-N_{0}^{e}\left(j w_{i}\right) D_{1}^{o}\left(j w_{i}\right)=0 \\
& m_{2,3}\left(j w_{i}\right)=D_{0}^{e}\left(j w_{i}\right) N_{1}^{o}\left(j w_{i}\right)-N_{0}^{o}\left(j w_{i}\right) D_{1}^{e}\left(j w_{i}\right)=0 \\
& m_{2,4}\left(j w_{i}\right)=D_{0}^{o}\left(j w_{i}\right) N_{1}^{o}\left(j w_{i}\right)-N_{0}^{o}\left(j w_{i}\right) D_{1}^{o}\left(j w_{i}\right)=0 \\
& m_{3,4}\left(j w_{i}\right)=D_{0}^{o}\left(j w_{i}\right) D_{1}^{e}\left(j w_{i}\right)-D_{0}^{e}\left(j w_{i}\right) D_{1}^{o}\left(j w_{i}\right)=0
\end{aligned}
$$

It is easy to see that the relationships from (27a) to (27f) considered by two are equivalent to a third equation, i.e.

equations (27a) and (27d) $\Longleftrightarrow$ equation (27b) equations (27a) and (27e) $\Longleftrightarrow$ equation (27c) equations (27d) and (27e) $\Longleftrightarrow$ equation (27f)
It follows that to study $\operatorname{Mat}_{I}(j w)=0$, it is necessary and sufficient to study only the 3 equations (27a), (27d) and (27e) instead of the 6 equations as initially set. Then, we have

$$
\begin{gathered}
\exists w_{i} \in \mathbb{R}^{+}{ }_{-\{0\}} \text { such that } \operatorname{Mat}_{I}\left(j w_{i}\right)=0 \\
\Longleftrightarrow \exists w_{i} \in \mathbb{R}^{+}{ }_{-\{0\}} \text { such that } \\
\left\{\begin{array}{l}
N_{0}^{o}\left(j w_{i}\right) N_{1}^{e}\left(j w_{i}\right)-N_{0}^{e}\left(j w_{i}\right) N_{1}^{o}\left(j w_{i}\right)=0 \\
D_{0}^{e}\left(j w_{i}\right) N_{1}^{o}\left(j w_{i}\right)-N_{0}^{o}\left(j w_{i}\right) D_{1}^{e}\left(j w_{i}\right)=0 \\
D_{0}^{o}\left(j w_{i}\right) N_{1}^{o}\left(j w_{i}\right)-N_{0}^{o}\left(j w_{i}\right) D_{1}^{o}\left(j w_{i}\right)=0
\end{array}\right.
\end{gathered}
$$

Finally, if there exist strictly positive real zeros $w_{i}$ such that $\operatorname{Mat}_{I}\left(j w_{i}\right)=0$, those will be given by the strictly positive real common zeros of (29).

\section{B. Conditions on $A_{0}^{e}\left(j w_{i}\right) A_{1}^{e}\left(j w_{i}\right)$ and $A_{0}^{o}\left(j w_{i}\right) A_{1}^{o}\left(j w_{i}\right)$}

In order to evaluate the signs of expressions $A_{0}^{e}\left(j w_{i}\right) A_{1}^{e}\left(j w_{i}\right)$ and $A_{0}^{o}\left(j w_{i}\right) A_{1}^{o}\left(j w_{i}\right)$ according to $w_{i}$ and in taking into account the relations from (27a) to (27f), these expressions are transformed as below

$$
\begin{aligned}
& A_{0}^{e}\left(j w_{i}\right) A_{1}^{e}\left(j w_{i}\right)=\psi^{T}\left(j w_{i}\right) \operatorname{Mat}_{R}\left(j w_{i}\right) \psi\left(j w_{i}\right) \\
& A_{0}^{o}\left(j w_{i}\right) A_{1}^{o}\left(j w_{i}\right)=\varphi^{T}\left(j w_{i}\right) \operatorname{Mat}_{R}\left(j w_{i}\right) \varphi\left(j w_{i}\right)
\end{aligned}
$$

with a matrix $\operatorname{Mat}_{R}\left(j w_{i}\right)$ as follows

$\operatorname{Mat}_{R}\left(j w_{i}\right)=\left(\begin{array}{cccc}n_{1,1}\left(w_{i}\right) & n_{1,2}\left(w_{i}\right) & n_{1,3}\left(w_{i}\right) & n_{1,4}\left(w_{i}\right) \\ n_{1,2}\left(w_{i}\right) & n_{2,2}\left(w_{i}\right) & n_{2,3}\left(w_{i}\right) & n_{2,4}\left(w_{i}\right) \\ n_{1,3}\left(w_{i}\right) & n_{2,3}\left(w_{i}\right) & n_{3,3}\left(w_{i}\right) & n_{3,4}\left(w_{i}\right) \\ n_{1,4}\left(w_{i}\right) & n_{2,4}\left(w_{i}\right) & n_{3,4}\left(w_{i}\right) & n_{4,4}\left(w_{i}\right)\end{array}\right)$

with

$$
\begin{aligned}
& n_{1,2}\left(w_{i}\right)=N_{0}^{e}\left(w_{i}\right) N_{1}^{o}\left(w_{i}\right)=N_{0}^{o}\left(w_{i}\right) N_{1}^{e}\left(w_{i}\right) \\
& n_{1,3}\left(w_{i}\right)=N_{0}^{e}\left(w_{i}\right) D_{1}^{e}\left(w_{i}\right)=D_{0}^{e}\left(w_{i}\right) N_{1}^{e}\left(w_{i}\right) \\
& n_{1,4}\left(w_{i}\right)=N_{0}^{e}\left(w_{i}\right) D_{1}^{o}\left(w_{i}\right)=D_{0}^{o}\left(w_{i}\right) N_{1}^{e}\left(w_{i}\right) \\
& n_{2,3}\left(w_{i}\right)=N_{0}^{o}\left(w_{i}\right) D_{1}^{e}\left(w_{i}\right)=D_{0}^{e}\left(w_{i}\right) N_{1}^{o}\left(w_{i}\right) \\
& n_{2,4}\left(w_{i}\right)=N_{0}^{o}\left(w_{i}\right) D_{1}^{o}\left(w_{i}\right)=D_{0}^{o}\left(w_{i}\right) N_{1}^{o}\left(w_{i}\right) \\
& n_{3,4}\left(w_{i}\right)=D_{0}^{e}\left(w_{i}\right) D_{1}^{o}\left(w_{i}\right)=D_{0}^{o}\left(w_{i}\right) D_{1}^{e}\left(w_{i}\right)
\end{aligned}
$$

and

$$
\begin{aligned}
& n_{1,1}\left(w_{i}\right)=N_{0}^{e}\left(w_{i}\right) N_{1}^{e}\left(w_{i}\right) \\
& n_{2,2}\left(w_{i}\right)=N_{0}^{o}\left(w_{i}\right) N_{1}^{o}\left(w_{i}\right) \\
& n_{3,3}\left(w_{i}\right)=D_{0}^{e}\left(w_{i}\right) D_{1}^{e}\left(w_{i}\right) \\
& n_{4,4}\left(w_{i}\right)=D_{0}^{o}\left(w_{i}\right) D_{1}^{o}\left(w_{i}\right)
\end{aligned}
$$

Consequently, $\operatorname{Mat}_{R}\left(j w_{i}\right)$ is a symmetric matrix. In the following theorem, a condition is given to check that $\operatorname{Mat}_{R}\left(j w_{i}\right)$ is a semi-definite positive and a no null matrix. To show that, it is necessary and sufficient to verify that the eigenvalues of this matrix are positive and not all null.

Theorem 3: Let us assume that there exists strictly positive reals $w_{i}$, the common zeros of the polynomials (29), then the matrix $\operatorname{Mat}_{R}\left(j w_{i}\right)$ is a positive semi-definite no null matrix if and only if the following inequality is verified.

$$
\begin{aligned}
& D_{0}^{o}\left(j w_{i}\right) D_{1}^{o}\left(j w_{i}\right)+D_{0}^{e}\left(j w_{i}\right) D_{1}^{e}\left(j w_{i}\right)+ \\
& N_{0}^{o}\left(j w_{i}\right) N_{1}^{o}\left(j w_{i}\right)+N_{0}^{e}\left(j w_{i}\right) N_{1}^{e}\left(j w_{i}\right)>0
\end{aligned}
$$

Proof: See Appendix. 


\section{NeW Formulation of the HuRWitzNESS OF $A_{\lambda}(s)$}

If the relation (34) is checked, the polynomial forms (12a) and (12b) are positive semi-definite. Then, this condition is not a sufficient constraint to guarantee that the forms (12a) and (12b) are positive definite. Consequently, the question which is now set by considering the equations (30a) and (30b) is the following: are there vectors $\psi\left(j w_{i}\right)$ and $\varphi\left(j w_{i}\right)$ satisfying one of the two relationships (35) or (36) below ?

$\forall w_{i} \in \mathbb{R}^{+}{ }_{-\{0\}}$, such that

$$
\begin{aligned}
& \left\{\begin{array}{ccc}
\operatorname{Mat}_{I}\left(j w_{i}\right) & = \\
\psi^{T}\left(j w_{i}\right) \operatorname{Mat}_{R}\left(j w_{i}\right) \psi\left(j w_{i}\right) & >0
\end{array}\right. \\
& \left\{\begin{array}{ccc}
\operatorname{Mat}_{I}\left(j w_{i}\right) & = \\
\varphi^{T}\left(j w_{i}\right) \operatorname{Mat}_{R}\left(j w_{i}\right) \varphi\left(j w_{i}\right) & > & 0
\end{array}\right.
\end{aligned}
$$

In this paragraph are given sufficient and necessary conditions to satisfy the two inequalities (12a) and (12b) or (35) and (36). First, let us give the following technical result.

Theorem 4: [13]. Let $P(s)$ be an univariate polynomial in $s$, then $P(s)$ can be written in the form of a sum of squares of terms (S.O.S) if and only if $P(s)$ is a positive semidefinite form.

The proof is immediate: see [13].

Now, we can present our main result.

Theorem 5: Let $G_{0}(j w)$ and $G_{1}(j w)$ be two systems defined by $N_{0}^{e}(j w), N_{1}^{e}(j w), D_{0}^{e}(j w), D_{1}^{e}(j w)$ and $N_{0}^{o}(j w)$, $D_{0}^{o}(j w), N_{1}^{o}(j w), D_{1}^{o}(j w)$ the even and odd parts of $N_{0}(j w), N_{1}(j w), D_{0}(j w), D_{1}(j w)$ respectively and computed similarly than (8) and (9). Let us assume that there exist two stable polynomials $A_{0}(s)$ and $A_{1}(s)$ of same degree and of same sign given by (5).

Then in the case where there exist strictly positive real common zeros $w_{i}$ of (29), the polynomial segment $A_{\lambda}(s)$ given by (3) is stable if and only if

a) for any $w_{i}, G_{0}(j w)$ and $G_{1}(j w)$ verify the two inequalities (37).

$$
\left\{\begin{array}{l}
\frac{N_{0}^{e}\left(j w_{i}\right)}{N_{1}^{e}\left(j w_{i}\right)}>0 \\
D_{0}^{o}\left(j w_{i}\right) D_{1}^{o}\left(j w_{i}\right)+D_{0}^{e}\left(j w_{i}\right) D_{1}^{e}\left(j w_{i}\right)+ \\
N_{0}^{o}\left(j w_{i}\right) N_{1}^{o}\left(j w_{i}\right)+N_{0}^{e}\left(j w_{i}\right) N_{1}^{e}\left(j w_{i}\right)>0
\end{array}\right.
$$

b) for these two systems $G_{0}(j w)$ and $G_{1}(j w)$, there exists a controller $C(s)$ defined by $X^{e}(j w), Y^{e}(j w), X^{o}(j w)$, $Y^{o}(j w)$, the odd and even parts of $X(j w)$ and $Y(j w)$ computed similarly than (8) and (9), such that one of the four below inequalities (38) is verified.

$$
\begin{cases}\left(N_{1}^{e}\left(j w_{i}\right) X^{e}\left(j w_{i}\right)\right)^{2}+w_{i}^{4}\left(N_{1}^{o}\left(j w_{i}\right) X^{o}\left(j w_{i}\right)\right)^{2}+ \\ \left(D_{1}^{e}\left(j w_{i}\right) Y^{e}\left(j w_{i}\right)\right)^{2}+w_{i}^{4}\left(D_{1}^{o}\left(j w_{i}\right) Y^{o}\left(j w_{i}\right)\right)^{2} \neq 0 \\ \left(N_{1}^{e}\left(j w_{i}\right) X^{o}\left(j w_{i}\right)\right)^{2}+\left(N_{1}^{o}\left(j w_{i}\right) X^{e}\left(j w_{i}\right)\right)^{2} & + \\ \left(D_{1}^{e}\left(j w_{i}\right) Y^{o}\left(j w_{i}\right)\right)^{2}+\left(D_{1}^{o}\left(j w_{i}\right) Y^{e}\left(j w_{i}\right)\right)^{2} & \neq 0 \\ \left(N_{0}^{e}\left(j w_{i}\right) X^{o}\left(j w_{i}\right)\right)^{2}+\left(N_{0}^{o}\left(j w_{i}\right) X^{e}\left(j w_{i}\right)\right)^{2} & + \\ \left(D_{0}^{e}\left(j w_{i}\right) Y^{o}\left(j w_{i}\right)\right)^{2}+\left(D_{0}^{o}\left(j w_{i}\right) Y^{e}\left(j w_{i}\right)\right)^{2} & \neq 0 \\ \left(N_{0}^{e}\left(j w_{i}\right) X^{e}\left(j w_{i}\right)\right)^{2}+w_{i}^{4}\left(N_{0}^{o}\left(j w_{i}\right) X^{o}\left(j w_{i}\right)\right)^{2}+ \\ \left(D_{0}^{e}\left(j w_{i}\right) Y^{e}\left(j w_{i}\right)\right)^{2}+w_{i}^{4}\left(D_{0}^{o}\left(j w_{i}\right) Y^{o}\left(j w_{i}\right)\right)^{2} \neq 0\end{cases}
$$

If there is none strictly positive real zero, common zeros of the polynomials (29), the polynomial segment $A_{\lambda}(s)$ is stable.

Proof: Let us assume that there is a positive semidefinite no null matrix $\operatorname{Mat}_{R}\left(j w_{i}\right)$ such that relation (34) holds. Now, let us check that for any $w_{i}$, there exist $\psi\left(j w_{i}\right) \neq 0$, and $\varphi\left(j w_{i}\right) \neq 0$ such that (35) or (36). In using the relationships (27a) to (27f), we observe that $\operatorname{Mat}_{R}\left(j w_{i}\right)$ have two writings, see Appendix. Furthermore, as this symmetric matrix is positive semi-definite, then it can be written in the forms (39) where $L\left(j w_{i}\right)$ and $\widetilde{L}\left(j w_{i}\right)$ are given by (40) by taking into account the relations (29)

$$
\begin{aligned}
& \operatorname{Mat}_{R}\left(j w_{i}\right)=L\left(j w_{i}\right) L^{T}\left(j w_{i}\right)=\widetilde{L}\left(j w_{i}\right) \widetilde{L}^{T}\left(j w_{i}\right) \\
& L^{T}\left(j w_{i}\right)=\sqrt{\frac{N_{0}^{e}\left(j w_{i}\right)}{N_{1}^{e}\left(j w_{i}\right)}}\left[N_{1}^{e}\left(j w_{i}\right) N_{1}^{o}\left(j w_{i}\right) D_{1}^{e}\left(j w_{i}\right) D_{1}^{o}\left(j w_{i}\right)\right] \\
& \widetilde{L}^{T}\left(j w_{i}\right)=\sqrt{\frac{N_{1}^{e}\left(j w_{i}\right)}{N_{0}^{e}\left(j w_{i}\right)}}\left[N_{0}^{e}\left(j w_{i}\right) N_{0}^{o}\left(j w_{i}\right) D_{0}^{e}\left(j w_{i}\right) D_{0}^{o}\left(j w_{i}\right)\right]
\end{aligned}
$$

Thus, the polynomial segment $A_{\lambda}(s)$ may be written in a strictly positive form. For that, it is necessary and sufficient to check (35) or (36), i.e. one of the four expressions above

$$
\begin{aligned}
& A_{0}^{e}\left(j w_{i}\right) A_{1}^{e}\left(j w_{i}\right)=\psi^{T}\left(j w_{i}\right) L\left(j w_{i}\right) L^{T}\left(j w_{i}\right) \psi\left(j w_{i}\right)>0 \\
& A_{0}^{o}\left(j w_{i}\right) A_{1}^{o}\left(j w_{i}\right)=\varphi^{T}\left(j w_{i}\right) L\left(j w_{i}\right) L^{T}\left(j w_{i}\right) \varphi\left(j w_{i}\right)>0 \\
& A_{0}^{e}\left(j w_{i}\right) A_{1}^{e}\left(j w_{i}\right)=\psi^{T}\left(j w_{i}\right) \widetilde{L}\left(j w_{i}\right) \widetilde{L}^{T}\left(j w_{i}\right) \psi\left(j w_{i}\right)>0 \\
& A_{0}^{o}\left(j w_{i}\right) A_{1}^{o}\left(j w_{i}\right)=\varphi^{T}\left(j w_{i}\right) \widetilde{L}\left(j w_{i}\right) \widetilde{L}^{T}\left(j w_{i}\right) \varphi\left(j w_{i}\right)>0
\end{aligned}
$$

These expressions (41) are equivalent to the following ones

$$
\begin{aligned}
& A_{0}^{e}\left(j w_{i}\right) A_{1}^{e}\left(j w_{i}\right)=\left\|L^{T}\left(j w_{i}\right) \psi\left(j w_{i}\right)\right\|^{2}>0 \\
& A_{0}^{o}\left(j w_{i}\right) A_{1}^{o}\left(j w_{i}\right)=\left\|L^{T}\left(j w_{i}\right) \varphi\left(j w_{i}\right)\right\|^{2}>0 \\
& A_{0}^{e}\left(j w_{i}\right) A_{1}^{e}\left(j w_{i}\right)=\left\|\widetilde{L}^{T}\left(j w_{i}\right) \psi\left(j w_{i}\right)\right\|^{2}>0 \\
& A_{0}^{o}\left(j w_{i}\right) A_{1}^{o}\left(j w_{i}\right)=\left\|\widetilde{L}^{T}\left(j w_{i}\right) \varphi\left(j w_{i}\right)\right\|^{2}>0
\end{aligned}
$$

Let us assume that the components of the column matrix $L\left(j w_{i}\right)$ and $\widetilde{L}\left(j w_{i}\right)$ are denoted $l_{j}\left(j w_{i}\right)$ and $\widetilde{l}_{j}\left(j w_{i}\right)$ respectively and the components of the vector $\psi\left(j w_{i}\right)$ and $\varphi\left(j w_{i}\right)$ are denoted $\psi_{j}\left(j w_{i}\right)$ and $\varphi_{j}\left(j w_{i}\right)$ respectively. Consequently, the forms (42) may be written as sum of squares of terms, see Theorem 4 by substituting $s$ by $w_{i}$. Therefore, the expressions (42) become

$$
\begin{aligned}
& A_{0}^{e}\left(j w_{i}\right) A_{1}^{e}\left(j w_{i}\right)=\sum_{j=1}^{j=4}\left(l_{j}^{T}\left(j w_{i}\right) \psi_{j}\left(j w_{i}\right)\right)^{2}>0 \\
& A_{0}^{o}\left(j w_{i}\right) A_{1}^{o}\left(j w_{i}\right)=\sum_{j=1}^{j=4}\left(l_{j}^{T}\left(j w_{i}\right) \varphi_{j}\left(j w_{i}\right)\right)^{2}>0 \\
& A_{0}^{e}\left(j w_{i}\right) A_{1}^{e}\left(j w_{i}\right)=\sum_{j=1}^{j=4}\left(\widetilde{l}_{j}^{T}\left(j w_{i}\right) \psi_{j}\left(j w_{i}\right)\right)^{2}>0 \\
& A_{0}^{o}\left(j w_{i}\right) A_{1}^{o}\left(j w_{i}\right)=\sum_{j=1}^{j=4}\left(\widetilde{l}_{j}^{T}\left(j w_{i}\right) \varphi_{j}\left(j w_{i}\right)\right)^{2}>0
\end{aligned}
$$

By considering these relations (43) and the terms $l_{j}\left(j w_{i}\right)$, $\widetilde{l}_{j}\left(j w_{i}\right), \psi_{j}\left(j w_{i}\right), \varphi_{j}\left(j w_{i}\right)$ given by the relationships $(40)$, 
(22) and (23), the following inequalities are obtained

$$
\left\{\begin{array}{l}
\frac{N_{0}^{e}\left(j w_{i}\right)}{N_{1}^{e}\left(j w_{i}\right)}>0 \\
\left(N_{1}^{e}\left(j w_{i}\right) X^{e}\left(j w_{i}\right)\right)^{2}+w_{i}^{4}\left(N_{1}^{o}\left(j w_{i}\right) X^{o}\left(j w_{i}\right)\right)^{2}+ \\
\left(D_{1}^{e}\left(j w_{i}\right) Y^{e}\left(j w_{i}\right)\right)^{2}+w_{i}^{4}\left(D_{1}^{o}\left(j w_{i}\right) Y^{o}\left(j w_{i}\right)\right)^{2} \neq 0 \\
\left(N_{1}^{e}\left(j w_{i}\right) X^{o}\left(j w_{i}\right)\right)^{2}+\left(N_{1}^{o}\left(j w_{i}\right) X^{e}\left(j w_{i}\right)\right)^{2}+ \\
\left(D_{1}^{e}\left(j w_{i}\right) Y^{o}\left(j w_{i}\right)\right)^{2}+\left(D_{1}^{o}\left(j w_{i}\right) Y^{e}\left(j w_{i}\right)\right)^{2} \neq 0
\end{array}\right.
$$

and

$$
\left\{\begin{array}{l}
\frac{N_{1}^{e}\left(j w_{i}\right)}{N_{0}^{e}\left(j w_{i}\right)}>0 \\
\left(N_{0}^{e}\left(j w_{i}\right) X^{o}\left(j w_{i}\right)\right)^{2}+\left(N_{0}^{o}\left(j w_{i}\right) X^{e}\left(j w_{i}\right)\right)^{2}+ \\
\left(D_{0}^{e}\left(j w_{i}\right) Y^{o}\left(j w_{i}\right)\right)^{2}+\left(D_{0}^{o}\left(j w_{i}\right) Y^{e}\left(j w_{i}\right)\right)^{2} \neq 0 \\
\left(N_{0}^{e}\left(j w_{i}\right) X^{e}\left(j w_{i}\right)\right)^{2}+w_{i}^{4}\left(N_{0}^{o}\left(j w_{i}\right) X^{o}\left(j w_{i}\right)\right)^{2}+ \\
\left(D_{0}^{e}\left(j w_{i}\right) Y^{e}\left(j w_{i}\right)\right)^{2}+w_{i}^{4}\left(D_{0}^{o}\left(j w_{i}\right) Y^{o}\left(j w_{i}\right)\right)^{2} \neq 0
\end{array}\right.
$$

Hence, this theorem is proved.

\section{CONCLUSION}

In this paper has been given a checkable method to test the simultaneous stabilizability of a segment of systems defined by (1). We hope that our algebraic conditions that are given here, can be extrapolated for the synthesis of robust and simultaneous controller.

\section{APPENDIX}

To show that the symmetric matrix $\operatorname{Mat}_{R}\left(j w_{i}\right)$ such as (31) is semidefinite positive and no null, it suffices to compute the eigenvalues of this matrix and to check that they are positive and not all null. For that let us consider a first case with the matrix $\operatorname{Mat}_{R}\left(j w_{i}\right)$ given by the relations from (33a) to (33d) and the right side of the equations from (32a) to (32f). We may deduce that in the first case, we get

$$
\begin{aligned}
& \operatorname{det}\left(\operatorname{Mat}_{R}\left(j w_{i}\right)-\lambda I\right)= \\
& -N_{1}^{e}\left(j w_{i}\right) * D_{0}^{e}\left(j w_{i}\right)^{2} * D_{1}^{o}\left(j w_{i}\right)^{2} * N_{0}^{o}\left(j w_{i}\right) * N_{0}^{e}\left(j w_{i}\right) * \\
& N_{1}^{o}\left(j w_{i}\right)+D_{0}^{e}\left(j w_{i}\right)^{2} * D_{1}^{o}\left(j w_{i}\right)^{2} * N_{0}^{o}\left(j w_{i}\right) * N_{1}^{o}\left(j w_{i}\right) * \lambda+ \\
& D_{0}^{e}\left(j w_{i}\right)^{2} * D_{1}^{o}\left(j w_{i}\right)^{2} * N_{0}^{e}\left(j w_{i}\right)^{2} * N_{1}^{o}\left(j w_{i}\right)^{2}+N_{1}^{e}\left(j w_{i}\right) * \\
& D_{0}^{e}\left(j w_{i}\right)^{2} * D_{1}^{o}\left(j w_{i}\right)^{2} * N_{0}^{e}\left(j w_{i}\right) * \lambda-D_{0}^{e}\left(j w_{i}\right)^{2} * D_{1}^{o}\left(j w_{i}\right)^{2} * \lambda^{2}+ \\
& N_{1}^{e}\left(j w_{i}\right) * D_{0}^{e}\left(j w_{i}\right) * D_{1}^{o}\left(j w_{i}\right)^{2} * D_{1}^{e}\left(j w_{i}\right) * N_{0}^{o}\left(j w_{i}\right)^{2} * N_{0}^{e}\left(j w_{i}\right)- \\
& D_{0}^{e}\left(j w_{i}\right) * D_{1}^{o}\left(j w_{i}\right)^{2} * D_{1}^{e}\left(j w_{i}\right) * N_{0}^{o}\left(j w_{i}\right)^{2} * \lambda-D_{0}^{e}\left(j w_{i}\right) * \\
& D_{1}^{o}\left(j w_{i}\right)^{2} * D_{1}^{e}\left(j w_{i}\right) * N_{0}^{o}\left(j w_{i}\right) * N_{0}^{e}\left(j w_{i}\right)^{2} * N_{1}^{o}\left(j w_{i}\right)-D_{0}^{e}\left(j w_{i}\right) * \\
& D_{1}^{o}\left(j w_{i}\right)^{2} * D_{1}^{e}\left(j w_{i}\right) * N_{0}^{e}\left(j w_{i}\right)^{2} * \lambda+D_{0}^{o}\left(j w_{i}\right) * N_{1}^{e}\left(j w_{i}\right) * \\
& D_{0}^{e}\left(j w_{i}\right) * D_{1}^{o}\left(j w_{i}\right) * D_{1}^{e}\left(j w_{i}\right) * N_{0}^{o}\left(j w_{i}\right) * N_{0}^{e}\left(j w_{i}\right) * N_{1}^{o}\left(j w_{i}\right)- \\
& D_{0}^{o}\left(j w_{i}\right) * D_{0}^{e}\left(j w_{i}\right) * D_{1}^{o}\left(j w_{i}\right) * D_{1}^{e}\left(j w_{i}\right) * N_{0}^{o}\left(j w_{i}\right) * N_{1}^{o}\left(j w_{i}\right) * \lambda- \\
& D_{0}^{o}\left(j w_{i}\right) * D_{0}^{e}\left(j w_{i}\right) * D_{1}^{o}\left(j w_{i}\right) * D_{1}^{e}\left(j w_{i}\right) * N_{0}^{e}\left(j w_{i}\right)^{2} * N_{1}^{o}\left(j w_{i}\right)^{2}- \\
& D_{0}^{o}\left(j w_{i}\right) * N_{1}^{e}\left(j w_{i}\right) * D_{0}^{e}\left(j w_{i}\right) * D_{1}^{o}\left(j w_{i}\right) * D_{1}^{e}\left(j w_{i}\right) * N_{0}^{e}\left(j w_{i}\right) * \\
& \lambda+D_{0}^{o}\left(j w_{i}\right) * D_{0}^{e}\left(j w_{i}\right) * D_{1}^{o}\left(j w_{i}\right) * D_{1}^{e}\left(j w_{i}\right) * \lambda^{2}-N_{1}^{e}\left(j w_{i}\right) * \\
& D_{0}^{e}\left(j w_{i}\right) * D_{1}^{e}\left(j w_{i}\right) * N_{0}^{o}\left(j w_{i}\right) * N_{0}^{e}\left(j w_{i}\right) * N_{1}^{o}\left(j w_{i}\right) * \lambda+D_{0}^{e}\left(j w_{i}\right) * \\
& D_{1}^{e}\left(j w_{i}\right) * N_{0}^{o}\left(j w_{i}\right) * N_{1}^{o}\left(j w_{i}\right) * \lambda^{2}+D_{0}^{e}\left(j w_{i}\right) * D_{1}^{e}\left(j w_{i}\right) * \\
& N_{0}^{e}\left(j w_{i}\right)^{2} * N_{1}^{o}\left(j w_{i}\right)^{2} * \lambda+N_{1}^{e}\left(j w_{i}\right) * D_{0}^{e}\left(j w_{i}\right) * D_{1}^{e}\left(j w_{i}\right) * \\
& N_{0}^{e}\left(j w_{i}\right) * \lambda^{2}-D_{0}^{e}\left(j w_{i}\right) * D_{1}^{e}\left(j w_{i}\right) * \lambda^{3}+N_{1}^{e}\left(j w_{i}\right) * D_{1}^{o}\left(j w_{i}\right)^{2} * \\
& N_{0}^{o}\left(j w_{i}\right)^{2} * N_{0}^{e}\left(j w_{i}\right) * \lambda-D_{1}^{o}\left(j w_{i}\right)^{2} * N_{0}^{o}\left(j w_{i}\right)^{2} * \lambda^{2}-D_{1}^{o}\left(j w_{i}\right)^{2} * \\
& N_{0}^{o}\left(j w_{i}\right) * N_{0}^{e}\left(j w_{i}\right)^{2} * N_{1}^{o}\left(j w_{i}\right) * \lambda-D_{1}^{o}\left(j w_{i}\right)^{2} * N_{0}^{e}\left(j w_{i}\right)^{2} * \lambda^{2}- \\
& D_{0}^{o}\left(j w_{i}\right) * N_{1}^{e}\left(j w_{i}\right) * D_{1}^{o}\left(j w_{i}\right) * D_{1}^{e}\left(j w_{i}\right)^{2} * N_{0}^{o}\left(j w_{i}\right)^{2} * N_{0}^{e}\left(j w_{i}\right)+
\end{aligned}
$$

$D_{0}^{o}\left(j w_{i}\right) * D_{1}^{o}\left(j w_{i}\right) * D_{1}^{e}\left(j w_{i}\right)^{2} * N_{0}^{o}\left(j w_{i}\right)^{2} * \lambda+D_{0}^{o}\left(j w_{i}\right) *$ $D_{1}^{o}\left(j w_{i}\right) * D_{1}^{e}\left(j w_{i}\right)^{2} * N_{0}^{o}\left(j w_{i}\right) * N_{0}^{e}\left(j w_{i}\right)^{2} * N_{1}^{o}\left(j w_{i}\right)+D_{0}^{o}\left(j w_{i}\right) *$ $D_{1}^{o}\left(j w_{i}\right) * D_{1}^{e}\left(j w_{i}\right)^{2} * N_{0}^{e}\left(j w_{i}\right)^{2} * \lambda-D_{0}^{o}\left(j w_{i}\right) * N_{1}^{e}\left(j w_{i}\right) *$ $D_{1}^{o}\left(j w_{i}\right) * N_{0}^{o}\left(j w_{i}\right) * N_{0}^{e}\left(j w_{i}\right) * N_{1}^{o}\left(j w_{i}\right) * \lambda+D_{0}^{o}\left(j w_{i}\right) * D_{1}^{o}\left(j w_{i}\right) *$ $N_{0}^{o}\left(j w_{i}\right) * N_{1}^{o}\left(j w_{i}\right) * \lambda^{2}+D_{0}^{o}\left(j w_{i}\right) * D_{1}^{o}\left(j w_{i}\right) * N_{0}^{e}\left(j w_{i}\right)^{2} *$ $N_{1}^{o}\left(j w_{i}\right)^{2} * \lambda+D_{0}^{o}\left(j w_{i}\right) * N_{1}^{e}\left(j w_{i}\right) * D_{1}^{o}\left(j w_{i}\right) * N_{0}^{e}\left(j w_{i}\right) * \lambda^{2}-$ $D_{0}^{o}\left(j w_{i}\right) * D_{1}^{o}\left(j w_{i}\right) * \lambda^{3}+N_{1}^{e}\left(j w_{i}\right) * D_{1}^{e}\left(j w_{i}\right)^{2} * N_{0}^{o}\left(j w_{i}\right)^{2} *$ $N_{0}^{e}\left(j w_{i}\right) * \lambda-D_{1}^{e}\left(j w_{i}\right)^{2} * N_{0}^{o}\left(j w_{i}\right)^{2} * \lambda^{2}-D_{1}^{e}\left(j w_{i}\right)^{2} * N_{0}^{o}\left(j w_{i}\right) *$ $N_{0}^{e}\left(j w_{i}\right)^{2} * N_{1}^{o}\left(j w_{i}\right) * \lambda-D_{1}^{e}\left(j w_{i}\right)^{2} * N_{0}^{e}\left(j w_{i}\right)^{2} * \lambda^{2}+N_{1}^{e}\left(j w_{i}\right) *$ $N_{0}^{o}\left(j w_{i}\right) * N_{0}^{e}\left(j w_{i}\right) * N_{1}^{o}\left(j w_{i}\right) * \lambda^{2}-N_{0}^{o}\left(j w_{i}\right) * N_{1}^{o}\left(j w_{i}\right) * \lambda^{3}-$ $N_{0}^{e}\left(j w_{i}\right)^{2} * N_{1}^{o}\left(j w_{i}\right)^{2} * \lambda^{2}-N_{1}^{e}\left(j w_{i}\right) * N_{0}^{e}\left(j w_{i}\right) * \lambda^{3}+\lambda^{4}$

After factorization and simplification of this expression, by taking the relationships (29) into account, we deduce that $\operatorname{det}\left(\operatorname{Mat}_{R}\left(j w_{i}\right)-\lambda I\right)$ has three null eigenvalues and one no null. This eigenvalue no null is the following

$$
\begin{aligned}
& D_{0}^{o}\left(j w_{i}\right) D_{1}^{o}\left(j w_{i}\right)+D_{0}^{e}\left(j w_{i}\right) D_{1}^{e}\left(j w_{i}\right)+ \\
& \quad N_{0}^{o}\left(j w_{i}\right) N_{1}^{o}\left(j w_{i}\right)+N_{0}^{e}\left(j w_{i}\right) N_{1}^{e}\left(j w_{i}\right)>0
\end{aligned}
$$

The proof is similar in the second case where the matrix $\operatorname{Mat}_{R}\left(j w_{i}\right)$ is defined by the relations from (33a) to (33d) and the left side of the equations from (32a) to (32f).

\section{ACKNOWLEDGMENT}

I thank Mr. M. Zasadzinski and Mr. H. Souley Ali for the discussions that I has allowed me to improve this presentation.

\section{REFERENCES}

[1] C. Abdallah, P. Dorato, F. Prez, and D. Docampo. Controller synthesis for a class of interval plants. Automatica, 31:pp. 341 - 343, 1995.

[2] C. Barlett, V. Hollot, and H. Lin. Root location of an entire polytope of polynomials: it suffices to check the edges. Mathematics of Controls, Signals and Systems, 1:pp 61-71, 1988.

[3] B. R. Barmish. New tools for robustness of linear systems. Macmillan Publishing Company, 1994. New-York.

[4] S. P. Bhattacharyya, H. Chappellat, and L. H. Keel. Robust Control, The parametric Approach. Prentice Hall, 1995.

[5] S. Bialas. A necessary and sufficient condition for the stability of convex combinations of stable polynomials and matrices. Bulletin of Polish Academy, 33:473-480, 1985.

[6] V. Blondel. A note on convex combinations of polynomials. IEEE TAC, 41(11):pp. 1690-1691, 1996.

[7] N. K. Bose. Test of hurwitz and shur properties of convex combination of complex polynomials. IEEE Transactions on Automatic Control, 36:1245-1247, 1989.

[8] G. Chockalingam and S. Dasgupta. Strong stabilizability of systems with multiaffine uncertainties and numerator denominator coupling. IEEE TAC, 39(9):pp. 1955-1958, 1994.

[9] K. Ghosh. Some new results on the simultaneous stabilizability of a family of single input, single output systems. Systems and Control Letters, 6(1):pp. 39-45, 1985.

[10] K. Ghosh. Simultaneous partial pole placement: A new approach to multimode system design. IEEE TAC, 31(5):pp. 440-443, 1986.

[11] S. P. Bhattacharyya H. Chapellat. A generalization of kharitonov's theorem: robust stability of interval plants. IEEE Transactions on Automatic Control, 34:306-311, 1989.

[12] V. Hollot and R. Tempo. On the nyquist envelope of an interval plant family. IEEE-TAC, 39(2):pp. 391-396, 1994.

[13] P.A. Parrilo. Structured semidefinite programs and semialgebraic geometry methods in robustness and optimization. California Institute of Technology, Pasadena, CA, USA, 2000.

[14] C. B. Soh. Generalization of the hermite-biehler theorem and applications. IEEE Transactions on Automatic Control, 35:222-225, 1990. 